\title{
MIOEPITELIOMA BENIGNO DE PARÓTIDA CON DIAGNÓSTICO INICIAL DE MALIGNIDAD. DESCRIPCIÓN DE UN CASO
}

\section{Benign parotid myoepithelioma with an initial diagnosis of malignancy. A case report}

Juan Miguel PALOMEQUE-VERA ${ }^{1}$; Emilia LÓPEZ-DE-HUELVA ${ }^{1}$; Encarnación FERNÁNDEZ-RUÍZ; María PLATERO-SÁNCHEZ-ESCRIBANO²; Sergio-Adrián RODRÍGUEZ-LOBALZO³; Manuel OLIVA-DOMÍNGUEZ $^{1}$

${ }^{1}$ Hospital Costa del Sol. Servicio de Otorrinolaringología. Marbella, Málaga. España. ${ }^{2}$ Hospital QuirónSalud Málaga. Servicio de Medicina Interna. Málaga. España. ${ }^{3}$ Hospital Costa del Sol. Servicio de Anatomía patológica. Marbella, Málaga. España.

Correspondencia: jm.palomeque@hotmail.com

Fecha de recepción: 25 de marzo de 2018

Fecha de aceptación: 14 de mayo de 2018

Fecha de publicación: 15 de mayo de 2018

Fecha de publicación del fascículo: 1 de septiembre de 2019

Conflicto de intereses: Los autores declaran no tener conflictos de intereses

Imágenes: Los autores declaran haber obtenido las imágenes con el permiso de los pacientes

Política de derechos y autoarchivo: se permite el autoarchivo de la versión post-print (SHERPA/RoMEO)

Licencia CC BY-NC-ND. Licencia Creative Commons Atribución-NoComercial-SinDerivar 4.0 Internacional

Universidad de Salamanca. Su comercialización está sujeta al permiso del editor

RESUMEN: Introducción: El mioepitelioma benigno es un tumor poco frecuente de las glándulas salivales. Es de bajo grado y representa aproximadamente al 1\% del total de los tumores benignos. Descripción: presentamos el caso de una paciente de 48 años de edad que acude a consulta de Otorrinolaringología por presentar una tumoración parotídea derecha. En la punción aspiración con aguja fina se obtiene positividad para carcinoma adenoideo quístico de alto grado. Posteriormente en el estudio histológico tras la parotidectomía suprafacial se diagnostica la lesión de mioepitelioma benigno. Discusión: La punción con aguja fina para el estudio citológico es poco sensible en estos tipos de tumores, pudiendo dar falsos positivos y negativos, que hacen que el mioepitelioma presente una seguridad diagnostica en la PAAF entorno al $75 \%$. Por lo que se precisa de estudios histológicos donde observamos como en el mioepitelioma se 


\section{MIOEPITELIOMA BENIGNO DE PARÓTIDA CON DIAGNÓSTICO INICIAL DE MALIGNIDAD. DESCRIPCIÓN DE UN CASO PALOMEQUE-VERA JM ET AL}

presenta un comportamiento similar al del tumor mixto, con ausencia de estructuras ductales y existencia de alteraciones cromosómicas en 12q. Conclusiones: El mioepitelioma benigno puede ser confundido por el carcinoma epitelial-mioepitelial o con el mioepitelioma maligno al presentar similitudes con la variedad benigna este último.

PALABRAS CLAVE: tumor parótida; parotidectomía; mioepitelioma.

SUMMARY: Introduction: The benign myoepithelioma is a rare tumor of the salivary glands. It is low grade and represents approximately $1 \%$ of the total benign lesions. Description: We present the case of a 48-year-old patient who visited the Otorhinolaryngology office for presenting a right parotid tumor. In fine needle aspiration, positivity is obtained for high-grade cystic adenoid carcinoma. Later in the histological study after the suprafacial parotidectomy, the lesion of benign myoepithelioma is diagnosed. Discussion: Fine needle aspiration for the cytological study is not very sensitive in these types of tumors, being able to give false positives and negatives, which make the myoepithelioma present a diagnostic security in the FNA around $75 \%$. Why histological studies are needed when we observe how in the myoepithelioma a behavior similar to mixed tumor occurs, with absence of ductal structures and the existence of chromosomal alterations in 12q. Conclusions: The benign myoepithelioma can be confused by epi-myoepithelial carcinoma or with malignant myoepithelioma, presenting similarities with the latter.

KEYWORDS: parotid tumor; parotidectomy; myoepithelioma.

\section{INTRODUCCIÓN}

El mioepitelioma benigno es un tumor poco frecuente de las glándulas salivales. Es de bajo grado y representa aproximadamente al $1 \%$ del total de los tumores benignos [1]. Deriva de las células mioepiteliales y se presenta encapsulado, de pequeño tamaño, con un crecimiento lento y casi siempre asintomático [2]. La variabilidad en la morfología celular y la composición del estroma conduce a dificultades de diagnóstico en la citología por aspiración con aguja fina, por lo tanto, a menudo requieren estudios histológicos y de inmunohistoquímica para el diagnóstico definitivo [1]. Entorno al 45-50\% de los casos afecta a la glándula parótida. La media de edad de aparición está cercana a los 40 años [3]. En las pruebas de imagen se observa una lesión de contornos suaves y márgenes bien definidos con aumento en el realce de la capsula en T1 y T2 con contraste [4].

\section{DESCRIPCIÓN}

Mujer de 48 años, sin antecedentes personales de interés, ni alergias medicamentosas. Acudió a consulta de otorrinolaringología por presentar una tumoración parotídea derecha preauricular de crecimiento progresivo, levemente dolorosa al tacto. En la exploración se palpaba una tumoración de unos $12 \mathrm{~mm}$ a $14 \mathrm{~mm}$ adyacente al margen superior del lóbulo superficial parotídeo derecho, de consistencia dura, adherida a planos y dolorosa a la palpación. No se encontraron adenopatías palpables en las cadenas ganglionares cervicales del cuello. En el momento de la exploración no se objetivaron signos de parálisis facial. El resto de la exploración ORL fue normal.

Se solicitaron pruebas complementarias: RMN (resonancia magnética nuclear), mediante la cual se observó una tumoración nodular de aproximadamente $11 \mathrm{~mm}$ adyacente al margen 


\section{MIOEPITELIOMA BENIGNO DE PARÓTIDA CON DIAGNÓSTICO INICIAL \\ DE MALIGNIDAD. DESCRIPCIÓN DE UN CASO}

PALOMEQUE-VERA JM ET AL

superior de la parótida, sin adenopatías cervicales

(Figura 1).

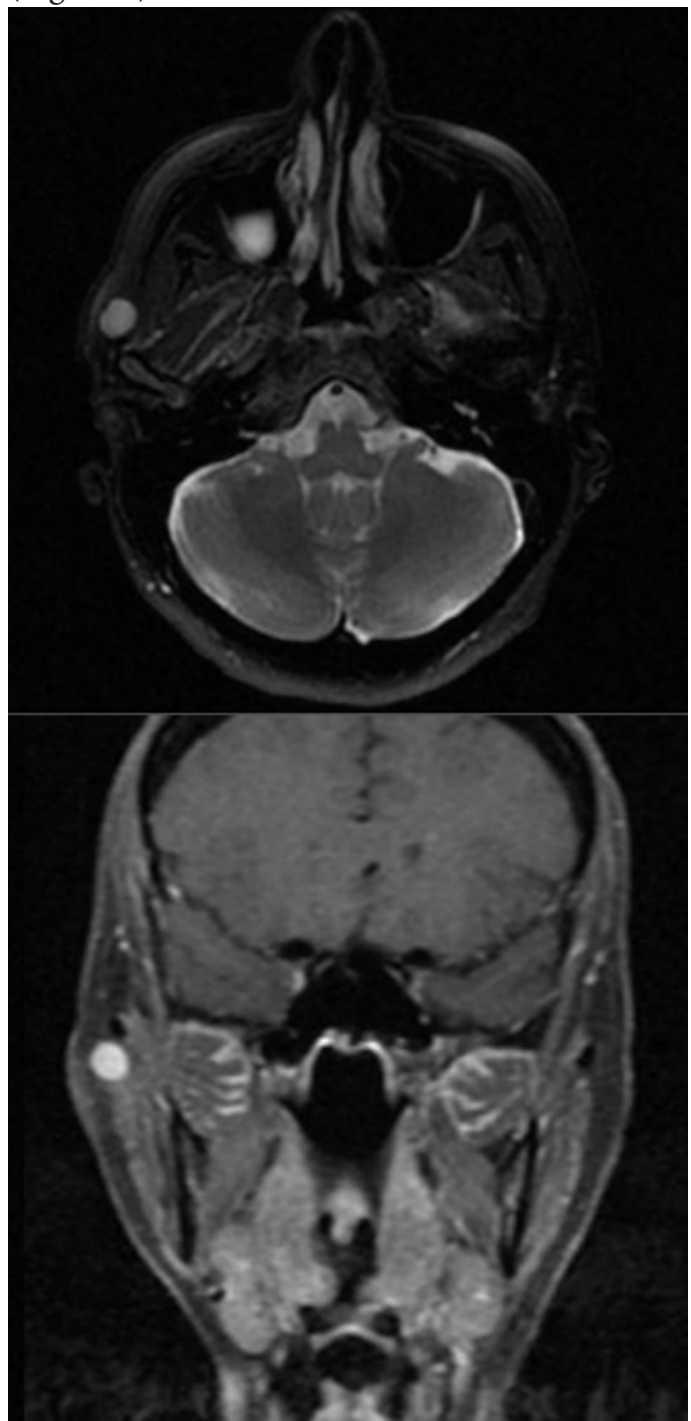

Figura 1. Imágenes de la resonancia magnética nuclear, con cortes axiales y coronales.

Posteriormente se realizó PAAF (punción aspiración con aguja fina) de la tumoración con diagnóstico de carcinoma adenoideo quístico de alto grado (Figura 2).

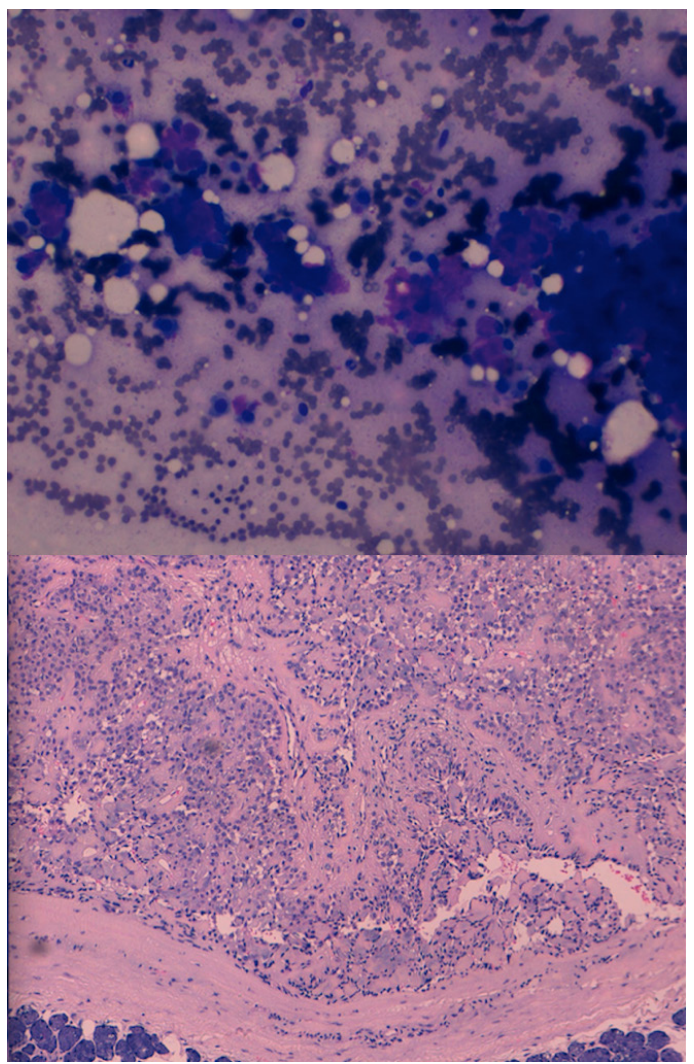

Figura 2. Imágenes de anatomía patológica. En la imagen de la izquierda, PAAF (20x): Citología con células neoplásicas sugestivas de carcinoma. En la imagen de la derecha, HE (10x): Tumoración en glándula parótida compuesto por células mioepiteliales que presente diferentes patrones celulares (fusiformes, plasmocitoides y patrón reticular) compatible con mioepitelioma benigno.

Dados los hallazgos, se presentó en comité oncológico y se decidió realizar parotidectomía superficial derecha con conservación del nervio facial (Figura 3) y vaciamiento cervical funcional derecho de las áreas I-IV. Tras la intervención no se observaron signos de parálisis facial ni otras complicaciones, a las 48 horas se retiró el drenaje aspirativo. La paciente se recuperó de forma satisfactoria, sin secuelas, salvo ligeras parestesias en zona preauricular y cervical alta que desaparecieron al cabo de varias semanas. Los resultados de la 


\section{MIOEPITELIOMA BENIGNO DE PARÓTIDA CON DIAGNÓSTICO INICIAL DE MALIGNIDAD. DESCRIPCIÓN DE UN CASO \\ PALOMEQUE-VERA JM ET AL}

pieza quirúrgica informaron resultado compatible con tejido parotídeo con mioepitelioma benigno, márgenes no afectos y adenopatías aisladas reactivas (Figura 2). Finalmente se decidió seguimiento de la paciente dada la benignidad de la lesión extirpada, en revisiones posteriores y un año después de la cirugía la paciente se encuentra asintomática y fue dada de alta de nuestra consulta.

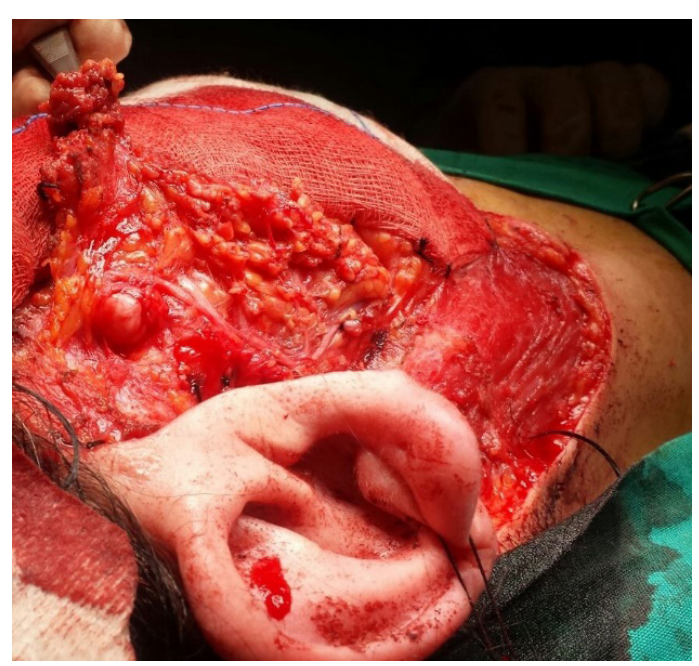

Figura 3. Imágenes de la tumoración y disección del nervio facial durante la parotidectomía suprafacial.

\section{DISCUSIÓN}

Los tumores de las glándulas salivales constituyen un grupo heterogéneo de neoplasias con una gran diversidad histomorfológica [5]. Pueden desarrollarse en cualquiera de ellas, siendo en la glándula parótida la localización más frecuente, entorno al $80 \%$, seguido de la afectación de la glándula submaxilar, entre el 10-15\% [3]. La probabilidad que tiene un tumor de ser maligno es tanto mayor cuanto menor sea el tamaño de la glándula salivar en la que asiente [5].

Los tumores mioepiteliales muestran grandes controversias en cuanto a la clasificación. Se pueden distinguir dos variedades de tumores mioepiteliales (benignos y malignos). El mioepitelioma benigno puede ser confundido por el carcinoma epitelialmioepitelial como ocurre en nuestro caso [5]. Desde el punto de vista histológico, el mioepitelioma benigno está compuesto hasta en un 5\% por células epiteliales ductales, algunos autores aceptan hasta un 10\% del área tumoral con diferenciación ductal y la presencia de estroma mucinoso $[3,4]$, para algunos representa una expresión morfología extrema del tumor mixto (diferenciación celular mioepitelial y ausencia de estructuras ductales) o con un cuadro morfológico intermedio que sería el adenoma de células basales [6].

En los tumores mioepiteliales se distinguen diferentes patrones: (celulares) células claras, plasmáticas o fusiformes y (arquitecturales) como el patrón reticular, solido, mixoide o combinación de varios tipos [6,7]. En el estudio de imnunohistoquímica muestras positividad celular para la proteína S100 y frente a anticuerpos de la vimentina y la citoqueratina [8].

El mioepitelioma maligno presenta similitudes con la variedad benigna. Se trata de un tumor de mediano a alto grado y se presenta principalmente en la glándula parótida en el 60\%. Histológicamente presenta células mioepiteliales, pero se observa atipia celular e infiltración neural. En el momento del diagnóstico pueden existir metástasis a distancia y tras su extirpación puede recidivar en el $60 \%$ de los casos [6].

El carcinoma epitelial-mioepitelial es un tumor maligno de bajo grado. A diferencia de los mioepiteliomas presentan una estructura tubular bifásica con una capa externa de células claras y una capa interna de células ductales, la capsula puede aparecer incompleta, a pesar de ello pueden confundirse en la PAAF. Su crecimiento es lento y suelen ser asintomáticos salvo que invadan al nervio facial, en este caso producen dolor [6]. Aparecen con mayor prevalencia en mujeres, entre la sexta y la séptica década de la vida y afectan con mayor frecuencia a la glándula parótida en el $75-80 \%$ de los casos. Suelen presentar metástasis a nivel de adenopatías 


\section{MIOEPITELIOMA BENIGNO DE PARÓTIDA CON DIAGNÓSTICO INICIAL DE MALIGNIDAD. DESCRIPCIÓN DE UN CASO \\ PALOMEQUE-VERA JM ET AL}

regionales en el 20-25\%. El índice de recurrencias tras su resección es del 20\% al 50\% [7].

En el caso del mioepitelioma maligno y del carcinoma epitelial-mioepitelial deben ser resecados con amplios márgenes de seguridad y valorar radioterapia posterior según aconsejan varios autores, sobre todo en tumores de más de cuatro centímetros [9].

La PAAF para el estudio citológico es poco sensible en estos tipos de tumores, pudiendo dar falsos positivos y negativos $[10,11]$, que hacen que el mioepitelioma presente una seguridad diagnostica en la PAAF entorno al 75\% [12]. Por lo que se precisa de estudios histológicos donde observamos como en el mioepitelioma se presenta un comportamiento similar al del tumor mixto, con ausencia de estructuras ductales y existencia de alteraciones cromosómicas en 12q [11]. El mioepitelioma maligno se presenta con elevada celularidad, existencia de pseudoinclusiones y de hendiduras nucleares y el carcinoma epitelialmioepitelial donde predominan los agregados de células basófilas y las células claras son escasas o inexistentes [12]. En nuestro caso aparecen numerosas células de aspecto epitelial con elevada celularidad, estructuras amorfas, de forma irregular, con pseudoinclusiones y hendiduras que hicieron pensar en un diagnostico inicial de malignidad.

Como observamos, en el diagnóstico anatomopatológico realizado previamente a la cirugía mediante la punción con aguja fina, el patólogo puede confundir el mioepitelioma benigno con el carcinoma o también con la variedad maligna del mioepitelioma. Siendo importante realizar un tratamiento quirúrgico correcto en estos tumores con un margen de seguridad a la hora de la exéresis de estas lesiones.

Respecto a la RMN, en los tumores benignos se muestra un nódulo bien definido, relativamente hipointensos en $\mathrm{T} 1 \mathrm{y}$ con intensidad de señal intermedia o elevada en secuencias T2 en los casos de tumores menores de $2 \mathrm{~cm}$ y con señal heterogénea $\mathrm{e}$ hiperintensa en el caso de grandes lesiones [13]. En tumores malignos se observa una baja intensidad en T1 y señal heterogénea en tumores de bajo grado e intermedia en los de alto grado en secuencias T2. En el caso especial del carcinoma adenoide quístico son lesiones hipointensas de intensidad intermedia en T1 y T2, la captación de contraste es homogénea [14].

\section{CONCLUSIONES}

Los tumores de las glándulas salivales constituyen un grupo heterogéneo de neoplasias con una gran diversidad histomorfológica. La afectación de la glándula parótida es la localización más frecuente, entorno al $80 \%$. El mioepitelioma benigno puede ser confundido por el carcinoma epitelial-mioepitelial o con el mioepitelioma maligno al presentar similitudes con la variedad benigna este último. La punción con aguja fina para el estudio citológico es poco sensible en estos tipos de tumores, pudiendo dar falsos positivos y negativos, que hacen que el mioepitelioma presente una seguridad diagnostica en la PAAF entorno al 75\%.

\section{AGRADECIMIENTOS}

Al servicio de Anatomía Patológica del Hospital Costa del Sol y en especial al Dr. Rodríguez Lobalzo y a la Dra. Rodrigo Fernández por cedernos las microfotografías del caso.

\section{BIBLIOGRAFÍA}

1. Weitzel M, Cohn JE, Spector H. Myoepithelioma of the Parotid Gland: A Case Report with Review of the Literature and Classic Histopathology. Case Rep Otolaryngol. 2017:4p. doi: 10.1155/2017/6036179.

2. Schneider V, Nobile A, Duvoisin B, Saglietti C, Bongiovanni M. Myoepithelioma of the parotid gland with extensive adipocytic metaplasia: Report of a case with intriguing aspects on fine needle aspiration and p63 immunohistochemical expression. Diagn Cytopathol. 2016;44:1090-3. 


\section{MIOEPITELIOMA BENIGNO DE PARÓTIDA CON DIAGNÓSTICO INICIAL \\ DE MALIGNIDAD. DESCRIPCIÓN DE UN CASO \\ PALOMEQUE-VERA JM ET AL}

3. Torres Gomez FJ, Lag Asturiano E, Torres Olivera FJ, Villar Rodriguez JL. Mioepitelioma parotideo. Estudio citológico, histológico e imnunohistoquímico. Rev Esp Patol. 2004; 4: 437-42.

4. Ding J, Wang W, Peng W, Zhou X, Chen T. MRI and CT imaging characteristics of myoepithelioma of the parotid gland. Acta Radiol. 2016; 57:837-43.

5. Li B, Yang H, Hong X, Wang Y, Wang F. Epithelialmyoepithelial carcinoma with highgrade transformation of parotid gland: A case report and literature review. Medicine. 2017; 96:88-9.

6. Gnepp Douglas R. Diagnostic Surgical Pathology of the Head and Neck. 2a ed. London: WB. Saunder Company; 2009.

7. Friedrich Reinhard E, Donath Karl. epithelialmyoepithelial carcinoma of the parotid gland with multiple distant metastases: A Case Report. J Oral Maxillofac Surg. 2000;58:690-4.

8. Alos L, Cardesa A, Bombi J. Myoepithelial tumors of salivary glands: a clinicopathologic, inmunohistochemical, ultrastructural and flow- cytometric study. Semin Diagn Pathol. 1996;13:13-47.
9. Inoue Yuko, Nomura Jouji, Hashimoto Masanori, Tagawa Toshiro. Epithelial myoepithelial carcinoma of the palate: a case report. J Oral Maxillofac Surg. 2001;59:1502-5.

10. El Naggar A, Lovell M, Callender D. et al. Cytogenetic analysis of a primary salivary gland myoepit-helioma. Cancer Genet Cytogenet. 1999;113:9-53.

11. Chieng D, Paulino A: Cytology of the myoepithelial carcinoma of the salivary gland. Cancer. 2002;96: 36-42.

12. Fletcher C. Tumors of the salivary glands. En: Fletcher C. Diagnostic Histopathology of Tumours. 1a ed. London: Churchill Livingstone; 2000. p. 231-311.

13. Harnsberger HR, Glastonbury CM, Michel MA, Koch BL. Diagnostic Imaging: Head and Neck. Amirsys. 2nd edition. 2011.

14. Tartaglione T, Botto A, Sciandra M, Gaudino S, Danieli L, Parrilla C, et al. Differential diagnosis of parotid gland tumours: which magnetic resonance findings should be taken in account? Acta Otorhinolaryngol Ital. 2015;35(5):314-20. 